\section{BOLLETTINO DELLA \\ SOCIETA' CEOCRAFICA ITALIANA}

OPEN ACCESS

Citation: V. Cocco (2020). (Un)Expected Contemporary Public Space. Bollettino della Società Geografica Italiana serie 14, 3(2): 55-64. doi: 10.36253/bsgi-1026

Copyright: (c) 2020 V. Cocco. This is an open access, peer-reviewed article published by Firenze University Press (http://www.fupress.com/bsgi) and distributed under the terms of the Creative Commons Attribution License, which permits unrestricted use, distribution, and reproduction in any medium, provided the original author and source are credited.

Data Availability Statement: All relevant data are within the paper and its Supporting Information files.

Competing Interests: The Author(s) declare(s) no conflict of interest.
Firenze University Press

www.fupress.com/bsgi

\title{
(Un)Expected Contemporary Public Space
}

\section{(In)atteso spazio pubblico contemporaneo}

\author{
VAleria Cocco \\ Dipartimento Metodi e Modelli per l'Economia, il Territorio e la Finanza, Sapienza Uni- \\ versità di Roma, Italia \\ E-mail: valeria.cocco@uniroma1.it
}

\begin{abstract}
The paper analyzes the contemporary concept of public space. It focuses the attention on the transformation of the traditional concept of public space into the idea of an alternative public space (i.e. collective space, open space, hybrid space, etc.). The methodology adopted for research purposes is mainly empirical. The case study analyzes the MAXXI museum in Rome, that shows a spontaneous birth of a (un) expected form of public space in the museum pole. This phenomenon expresses a clear need of an alternative, safe, cultural, innovative, contemporary, public space.
\end{abstract}

Keywords: cities, public space, museums.

Riassunto. L'articolo analizza il concetto contemporaneo di spazio pubblico. Focalizza l'attenzione sulla trasformazione del concetto tradizionale di spazio pubblico verso uno spazio pubblico alternativo (cioè uno spazio collettivo, aperto, ibrido, ecc.). La metodologia adottata a fini della ricerca è principalmente empirica. Il caso studio analizza il polo museale del MAXXI di Roma, che mostra una nascita spontanea di una forma (non) prevista di spazio pubblico nel polo museale. Questo fenomeno esprime la chiara necessità di uno spazio pubblico alternativo, sicuro, culturale, innovativo, contemporaneo.

Parole chiave: città, spazio pubblico, musei.

\section{Introduction}

This research is part of the recent debate about public space, "including all varieties of pseudo-public space" (Carmona 2019, 53); in particular, it analyzes the concept, the nature and the function of public space in urban areas, drawing an empirical analysis in Rome. The study moves from the evidence that contemporary public spaces do not always seem to coincide with "formal public spaces" (Carmona 2019, 47). In fact, even if the public spaces' planners had the ambition to design a well public space, this is not always meeting the reality (Carmona 2019).

The recent transformation of public, cultural and social spaces is dictated by the strong dynamism and fluidity of the city which has seen a response in the birth of a postmodern theoretical approach with reference to that part of 
literature defined as critical. From the new multidisciplinary lines of reflection on the interaction between individual, place, society and on social and territorial transformations, a renewed centrality emerges with reference to the relationship between the individual and the transformations that innervate the territory (Maggioli 2015), to the relationship between places and social subjects (Berdoulay, Entrikin 1998), to the geography of everyday life (Lindón e al. 2006). In this context, the strong link between individual and space, as well as the interpretation of microeconomic and social dynamics create a complex scenario characterized by many phenomena that are not easily decipherable (Innerarity, 2008). Thus, as economic and social geographies change, the transformation involves also the nature of public spaces (Galuzzi, Vitillo 2018).

Indeed, the contemporary public spaces could be seen as public or semi-public (or semi-private) urban areas acquired, more or less progressively, by the same communities (Hou 2010; Carmona 2019) in a process of re-appropriation of the city made by individuals and groups, and used as collective spaces. In particular, some authors (Francis e al. 2012; Gehl 2020) noticed that new public spaces are successful, while traditional public spaces are not. Thus, a reflection naturally arises: what are the elements that make public spaces successful and coherent with the need of the people?

According to Gehl (2020), in the contemporary society, people are looking for a space that must be comfortable, welcoming and livable (i.e. the square must have points of support as benches and sit walls to be seen as a public space). Carmona (2019) argues that "spaces become more meaningful as users interact with them" (Carmona 2019, 54). Other authors (Francis e al. 2012) seem to associate to public spaces a strong sense of community with the wellbeing, the feelings of safety and security.

Thus, in the XXI century cities, meeting and connection places could become public spaces and the extended use of public space must be seen as a development form of society (Gehl 2020). In other words, the great social transformations of the last decades have contributed to change over time the ways in which society has transformed spaces, places and forms of living, and, at the same time, experts have adopted a new opinion which has moved away from those classic theories which today appear short-sighted and unable to face existing reality and to propose alternative solutions consistent with the needs of individuals, and which place the concept of space in the declination of collective, open, public space at the center of a great literary debate.

Overcoming the debate about public space in the neoliberal approach view and in the critical view, the need to "re-theorise public space discourse on the basis of the actual experiences" (Carmona 2015; Carmona $2019,47)$ and the need to define the elements that make public space successful and coherent with the need of the people (Gehl 2020) emerge as relevant points of this research.

Indeed, the literature about the evolving of public space concept is various and wide, as wide is the renewed interest in how the urban fabric could affect the sense of community, whilst there is a lack of empirical research that analyzes the renewed concept of public space in relation to the collective use and practices, the association between sense of community and the quality of public space (Francis e al. 2012; Carmona 2019; Gehl 2020).

Thus, the research aims to focus on the empirical analyses of a case study involving the spontaneous creation of a public space. In particular, this paper draws on research conducted in Rome, in the area of the MAXXI Museum. The case study analyzes the use of a void - an area that was not built inside the MAXXI Museum, located in the Flaminio district of Rome - as a public space. In fact, according to the original project of the museum, for not very clear reasons, some of the buildings into the project were never built and the area remained an empty space. In this research the void had not to be interpreted in the declination of waste and residual space (Stravato 2010), but it could be defined as an open or collective space when a place of identity, socialization, meeting and/or leisure is created in that void (Albanese 2018). Thus, in this scenario, the phenomenon of space recovery is to be considered strictly connected to the concepts of identity and landscape where the contemporary citizen, living in a liquid space, tends to adapt changes in the surrounding context (Bauma, 2012; Berizzi 2018) and the frequent and contemporary processes and practices of re-appropriation by people (e.g. urban gardens, self-managed green spaces, places of cultural production, public spaces used for collective activities, etc.) act as a sign of vitality and dynamism of cities, as practices of freedom (Cellamare 2014). In this perspective, cities try to regain a cultural role to raise the quality of life through the re-appropriation of the territory (Albanese 2018) and the inhabitants seem to return to the center of the logic of urban development policies (Crosta 2010). In the midst of this cultural revolution emerges a renewed need of people to meet, for which cities increase their quality of life by assigning new collective values and meanings to emptiness (Cellamare 2014). In this regard, by reasoning around the concept of social identity of places and urban experience in individual local contexts of interaction (Zajczyk 
1991), the protagonist of citizens' daily life becomes the collective space, regardless of its private or public character (Cellamare 2016; Albanese 2018). Therefore, overcoming the functional vision of modern urban models, the loss of meaning of the clear division between public and private open spaces, their origin and ownership, and also the difference between internal and external spaces stands out (Albanese 2018), public or semi-public space could be defined as a space with collective use (Crosta 2000) and shared (Barnett, 2014), starting from the assumption that it is the social interaction and the action of individuals that make the use public of the territory (Barnett 2014; Crosta 2010).

In a nutshell, the research is moved by the desire to reconstruct functions and use by the population and verify if the MAXXI Museum could be an example of public space produced by the re-appropriation of citizens, showing the results of a survey carried out in the MAXXI Museum pole.

The construction of the contribution is characterized by a first part in which I will briefly reconstruct the functional profile of the Flaminio district of Rome and a morphological analysis of the MAXXI Museum space; then, in the second part of the research, I will focus my attention on the aim and the real use of the MAXXI Museum pole, highlighting the empirical findings and results of a survey carried out in the MAXXI Museum. In particular, the methodology for collecting information was articulated in direct observation, questionnaires addressed to the users of the MAXXI not-built area, extensive interviews both to the users of the space and to relevant people connected with the MAXXI (i.e. the deputy artistic director of the Museum). The survey was carried out in July 2018 at different hours' time and days, in order to guarantee a more complete view of the sample - 150 users interviewed, of which 123 respondents -.

Moreover, in consideration of the fact that Covid-19 pandemic has changed - and will, probably, continue to change - the needs of individuals, the research intends to start reflections about the improvement policies addressed to create a cultural ecosystem and the perspectives of contemporary public spaces integrated with museums and cultural heritage during and after the pandemic times.

\section{The functional profile of the Flaminio district and the morphological analysis of the MAXXI Museum}

The city of Rome is undoubtedly a case study of considerable complexity. It has been affected for millennia by urban growth effects (i.e. from the enlargement of the
Imperial Walls to the creation of XX century suburbs). The city of Rome, therefore, appears to be born spontaneously and discontinuously, exception for some cases.

The area object of the research is part of the Flaminio district that since the III century $\mathrm{BC}$, represented the north gateway to the city, thanks to the construction of the Via Flaminia street. The first settlements date back to the late nineteenth century, when the Savoy's kingdom built the walls on the Tiber river to stem the frequent floods, which made the area located inside the bend of the Tiber river uninhabitable.

The area, originally characterized by the presence of industrial plants and barracks, was designed by the Master Plan of 1909, during the term of Mayor Nathan. It became a new district, officially established in 1921; in fact, the first residential middle-income class houses - "Villa Riccio" and "Piccola Londra" - were built in the 1920s. In particular, the geographical location of the district designs a sort of urban enclave inside the bend of the river, despite the Master Plan of 1909 prepared a project of infrastructure of the area to avoid isolation. Three bridges were designed in 1909, to create a link between Flaminio and Prati districts - just on the opposite side of the Tiber river -, however, only one of these was built: the so-called Ponte della Musica, inaugurated much later, just in 2011.

More in general, the functional profile of the district has mainly been oriented to the sectors of culture, entertainment and sport. Different venues, located in the area and in its surroundings, have definitely marked its sporting and recreational character: since the 1911 International Exhibition, the Flaminio district has been characterized by the construction of the Villa Glori Racetrack Stadium and the National Stadium; in between the 1920s and 1930s there was the construction of the Foro Italico, a large complex of facilities for games and sport, and, later, in the 1960s, the construction of the Olympic Village in the surroundings of the Flaminio district, previously occupied by the shacks of the so-called Campo Parioli (Salvo 2014); thus, between 1998 and 2010 there was the construction of the MAXXI Museum with the aim of recovering the abandoned barracks in Guido Reni street, taking part to a season of re-launching the image and the global competitiveness of Rome (Scott 2001; Paul 2004).

After the framing of the district, here, the focus moves on the morphological analysis of the MAXXI Museum. The project of the museum started in 1998, with a public contest organized by the Special Superintendency for Contemporary Art. The contest won by the archistar Zaha Hadid saw the inauguration of the Museum in 2010 . 


\section{Via G.P. Pannini}

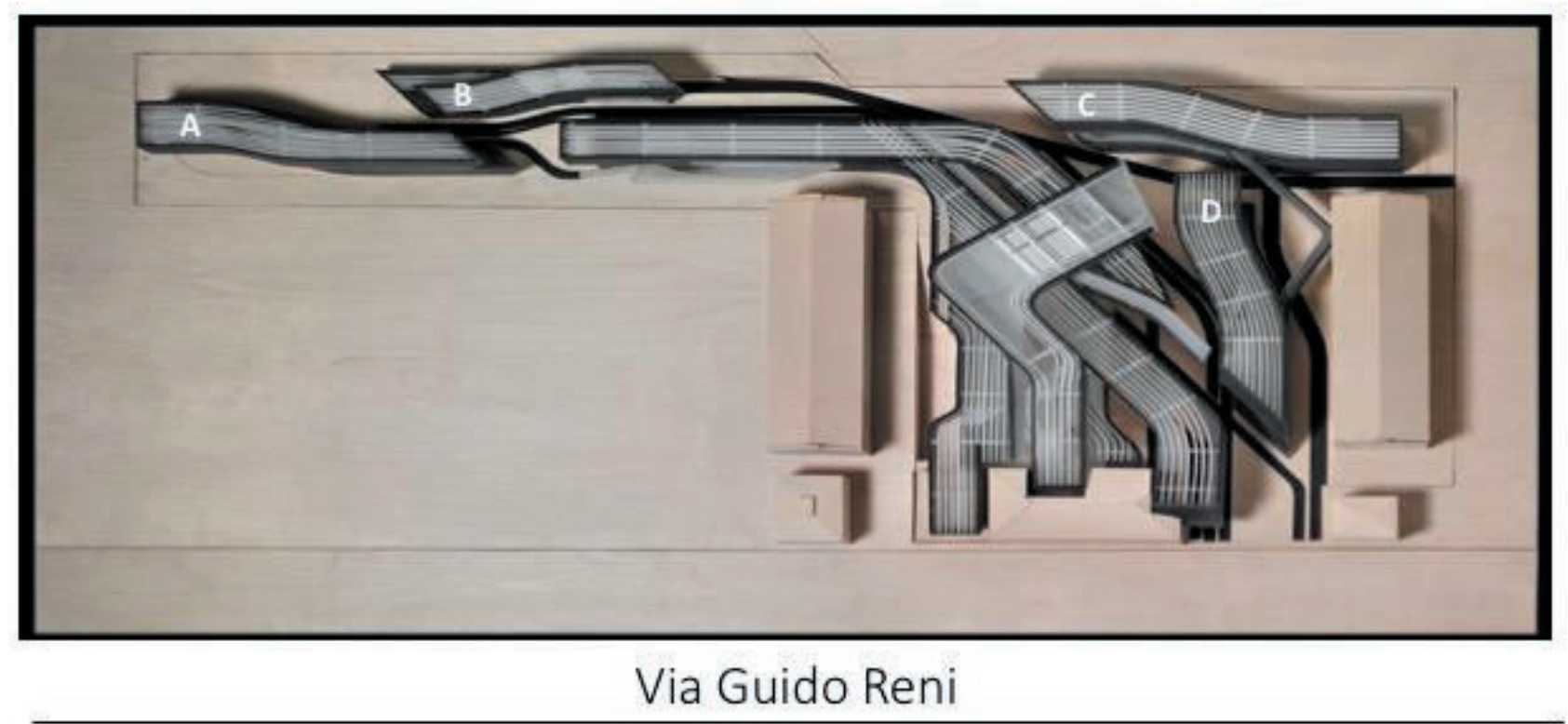

Figure 1. Original project MAXXI 1998-2003. Source: modified by the author on project 1998-2003 from the website https://www.artribune.com/wp-content/uploads/2017/05/02-Collezioni-MAXXI-Architettura-Archivio-Zaha-Hadid-MAXXI-Museo-nazionale-delle-arti-delXXI-secolo-Roma-1998-2003.jpg

According to the original project (1998-2003), the museum pole designed by Zaha Hadid should have occupied about 30,000 square meters, integrating part of the pre-existing military structures with a new building characterized by an L-shaped plan (Fig. 1). The current buildings group creating the museum appears, however, different from the original project, that's why, the architect herself defined the MAXXI her unfinished work (Hadid, Betsky, 2009).

In the first competition phase 1998-2003, the project envisaged, in fact, the construction of four extra buildings compared to the MAXXI of nowadays and indicated with the letters A, B, C, D in the Figure 1. The four buildings have never been built: two buildings (buildings $\mathrm{A}$ and $\mathrm{B}$ ) would have had to rise on the opposite side of the barracks of Guido Reni street, in the direction of G.P. Pannini street, and two more (buildings C and D) had to saturate the space between the museum exhibition area and the library and restaurant area, thus, totally occupying the nowadays outdoor space.

The choice not to build the four buildings planed in the original project seems to have been dictated both by structural problems due to the complexity of the new building and by the lack of public funds. In particular, according to the MAXXI artistic deputy director Mrs. Saroli, the "square" emerges from the lack of that cen- tral buildings ( $\mathrm{C}$ and $\mathrm{D})$, certainly due to an economic problem occurred. Zaha Hadid did not conceived neither designed the construction of the public space for the outdoor, but conceived a large space for the indoors - in fact, when there are many visitors there is not a crowd in the exhibition area -. The void that emerged by the missing construction of the building $\mathrm{C}$ and $\mathrm{D}$ create an empty space that became object of citizens' reappropriation.

In any case, as a consequence of the only partial realization of the original competition project, the outdoor area was set up with chairs and benches, creating an element able to spur the transformation of the area in a sort of public or collective space. Indeed, in consideration of the fact that according to Gehl (2020) squares must have points of support as benches and sit walls to be seen as a public space, the MAXXI outdoor area could fall into this feature. In particular, by a direct observation and empirical researches (\$.3), it emerges that over time the outdoor area of the MAXXI consolidate its role as a sort of public space, through its appropriation by citizens, witnessed also by the various origin of users detected in the outdoor area of the museum.

The unfinished project of the MAXXI Museum opens a reflection about public space and its integration with cultural ecosystem of the city. Therefore, in 
light of these first analyzes, the MAXXI used as a collective or public space could be included in the theoretical debate about the ownership of the spaces and about the definition of a contemporary public spaces into a semipublic (or semi-private) urban area (Hou 2010). In much of the literature, the space to be public had to be open and unrestricted; whilst, the MAXXI, being a museum pole, has restrictions, first of all, in terms of opening hours' time, therefore, from this point of view would not be considered as a public space. In spite of this, the MAXXI appear, by the empirical research findings (\$.3) and by direct observation, mainly used as a public space. Indeed, according to Nemeth (2012) restrictions on use apply to all spaces - regardless of private and public ownership -, and their amenity value is independent of this factor. In fact, the residents of the district and the other citizen users of the area are aware that MAXXI museum is a space managed and granted in private use ${ }^{1}$; nevertheless, despite the limits created by the private management of the space (i.e. it is close one day a week, it is open from $10 \mathrm{am}$ to $7 \mathrm{pm}$, etc.) the citizens choose this area, instead to a classic park or traditional public space (i.e. squares, etc.), because the limits and the restrictions of the private ownership assume a positive feature creating a sort of enclave to the rest of the city that make the people feel safe and protected from eventual risks and degradation of the city ${ }^{2}$.

Actually, the MAXXI museum pole manages to be an enclave, creating for users a sort of security bubble from the city, and, at the same time, it appears integrated into the urban context, into the city, as a multifunctional space aimed at citizens. According to Mrs. Saroli, the integration with the district has been an important element since the original project ${ }^{3}$. In the intentions of

\footnotetext{
${ }^{1}$ One of the interviewed inhabitants of the district witnessed the facts: "The money is over and so they have not finished the MAXXI, as originally planned. There, where we spend some time in the afternoon, there should have been a museum exhibition building. So, they did not think about making the MAXXI with a public space, but it happened. What then, we spend time there, but it is not really a public space. Monday is closed" (Flaminio inhabitant's interview, 2018).

2 "We come from the area Prati - Delle Vittorie, there is a park near our house in Piazza del Fante, but it is dirty. We are part of the district committee, but we cannot do anything, it is not safe for children. There is only the dog park there. So, once a week we come here, at MAXXI with the children" (Users of the MAXXI, interview, 2018).

${ }^{3}$ It is also witnessed by the deputy artistic director of the Museum, Mrs. Donatella Saroli - interview made by the author in 2018 -: "The museum staff ... many live in the neighborhood and also with foreign artists at dinner you are in the neighborhood. Then we organize visits that start from the museum and continue in the neighborhood. The museum is always related to the district. It is a museum of architecture, so it cannot do without the neighborhood. Zaha Hadid thinks of a space that does not have to separate the neighborhood" (translated by the author from Italian, 2018).
}

the Anglo-Iraqi architect Zaha Hadid (Hadid, Betsky 2009), the MAXXI had to be a multifunctional space, based on culture and creativity, a sort of urban campus addressed to different users; in fact, it includes a restaurant, a bar, a library, a bookshop, an area for consulting archives. Zaha Hadid work is defined by some authors (Guccione, Ciorra 2017) as a revolutionary investigation on the border between urban planning, architecture and design, which transforms the museum into a place suited to the encounter and integration of different cultures, social classes and ages. Thus, the MAXXI Museum is characterized by a modern and international scope; it is a stimulating space and a conducive environment to create an integration area that make the space to be perceived as open minded and international.

\section{Methodology}

The research draws the results of questionnaires addressed to the users of the MAXXI, in particular in the not-built area of the museum pole. The questionnaire was submitted to a sample of 150 users, of which 123 were respondents. The questionnaire was submitted on different days and hours' time to ensure a more complete and accurate use of the structure (i.e. afternoon, lunch time, morning). It has been used the snowball method of sampling and the questionnaires were proposed to about the $80-90 \%$ of the people gravitating in the area of the MAXXI outdoor space in the 2 hours' time of investigation. The sample involved the people that were located in the MAXXI outdoor area in between the investigation times ( 2 hours' time for every investigation). Indeed, in consideration of the fact that to reach the main entrance of the museum and exhibition buildings it was necessary to walk through the outdoor area, and considering that the permanence into the museum exhibition spaces it is about 2 hours, it was defined a time of investigation of 2 hour to be able to intercept flows of people presents in the outdoor area as different kind of visitors. Albeit, the structure of the questionnaire is made by direct and short questions, requiring in total about 5 minutes' answer time. In fact, even if other information i.e., the socio-cultural users' characters, etc. - could be collected to obtain interesting aspect to deepen, then the main goal of the study was focused on the analysis of the use of the space by citizens; therefore, the strategy of short questionnaire turned out to be beneficial and allowed to obtain a high average of the respondents ( $82 \%$ of respondents). 


\section{Finding and results emerged from the surveys}

The research aim is to analyze the actual use of the MAXXI museum pole outdoor area. Thus, to have a geographical framing of the flows of users, the investigation started from the origin of visitors. The expected results foresee to obtain a more consistent flow of residents of the Flaminio district (Municipality II) rather than other districts, considering the MAXXI as an alternative space to the other collective spaces of the district. Instead, even if a dense concentration of Flaminio district's residents as MAXXI outdoor area users is evident, the findings show that the MAXXI is able to attract flows of citizens from different areas of the city (peripheral areas, city center, etc.), and not only belonging to the closest districts. In particular, the $24 \%$ of respondents are resident in Flaminio district and $31 \%$ come from districts not far from the Flaminio in details, $15 \%$ come from Prati district, $7 \%$ Balduina and Monte Mario area, 6\% Aurelio, 4\% Parioli district and $4 \%$ in the Fleming-Vigna Clara districts - and the remaining $42 \%$ come from other districts both central and periferical ones and even areas just outside the city (i.e. Pigneto, Piazza Bologna, Castelli Romani, Viterbo, Latina, etc.) - or the respondents did not indicate their own origin (Fig. 2).

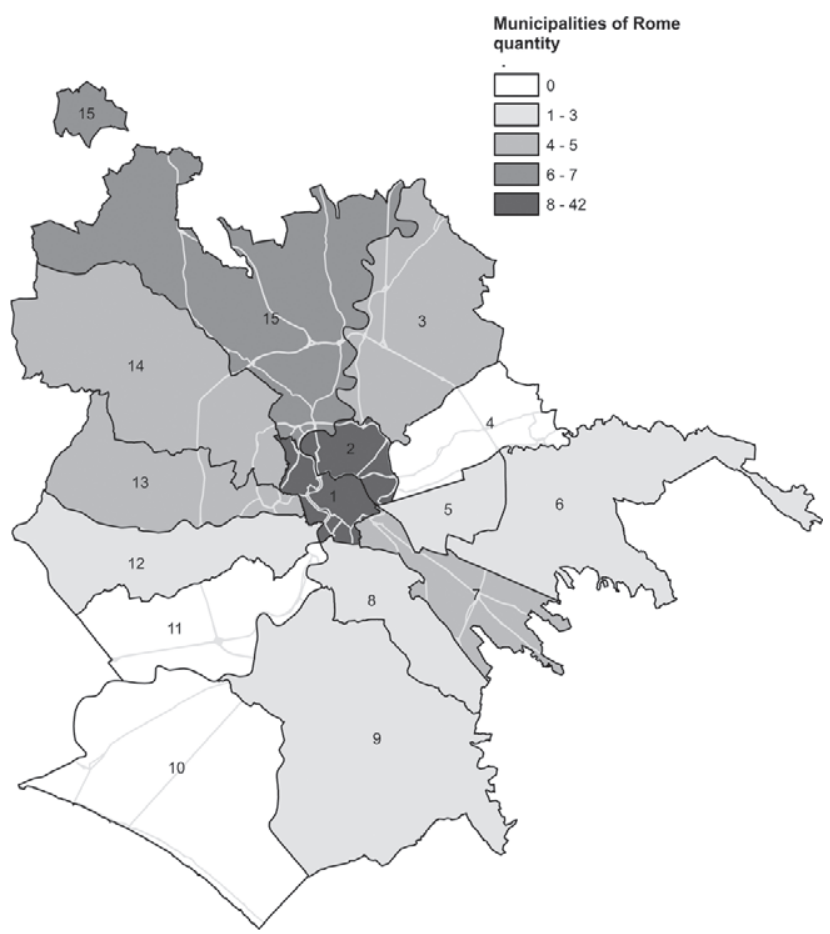

Figure 2. Origin of MAXXI users in the Roman Municipalities. Source: author's elaboration on data questionnaire 2018 (2021).
As it is clear, some people with origin of different districts could be workers in the area of the Flaminio or could gravitate in that area for other reasons. Thus, some information that could help to define the flows of the MAXXI users and to complete the origins of the users could be the transport vehicle used and the time spent to reach the MAXXI. The results of the survey highlight a quite homogeneous population in those who spent less than 10 minutes to reach the MAXXI - regardless of the transport vehicle used to reach it - (38\%), those who spent between 10 and 20 minutes (30\%), and those who spent more than 20 minutes (32\%). Indeed, it should be considered that the time to reach the museum center is not necessarily linked to the place of residence, but rather to the workplace in the Flaminio district, or in the neighboring districts. Therefore, it could be interesting to match the information "time spent to reach the MAXXI" with the transport vehicles used to go there. The $26 \%$ of the users reach the MAXXI by foot and the $2 \%$ by bike. This information matches quite well with the users that are also Flaminio residents (24\%).

Thus, it could likely to be that the ones who used no transportation vehicles to reach the MAXXI are the same who live in the Flaminio district and the little gap of the two percentages could belong, for example, to those who work in the Flaminio district and use the area for lunch break. Thus, $72 \%$ of the sample use a motor vehicle (bus, car, cab, etc.) to reach the museum that could match with those who spent more than 10 minutes and more than 20 minutes and in minimum percentage (around $5-10 \%$ ) to those who spent less than $10 \mathrm{~min}$ utes. In particular, the $14 \%$ of users reach the museum pole by bus and the $58 \%$ by car or motorcycle. The consistent number of users interviewed (58\%) driving to the MAXXI could be favored and explained by the large parking spaces just in front of the main entrance of the museum complex and in the nearby Olympic Village district. Thus, even excluding the $6 \%$ of the sample that use the outdoor area of the MAXXI for lunch break from work - some of them are residents outside the city of Rome and thus they could need the car or the bus to go work - still about the $66 \%$ of the users of the space use car/motorcycle or bus to reach the MAXXI for other reasons. Therefore, it comes naturally the wish to understand the reason why people are taking the car/motorcycle to reach the museum complex.

More in general, the aim of this research is to analyze the actual and main use of the outdoor space of the MAXXI museum and define the functional profile of the museum pole and the reason why people use it. The reason of the use of the space shows that just $12 \%$ of the interviewees were in the MAXXI museum for visiting 
the exhibitions, and among them $24 \%$ visited the exhibition spaces for the first time. More than $50 \%$ of the interviewed sample uses the MAXXI as a leisure place and a space for study and/or for work. In fact, from these results emerges that the majority of the MAXXI users used the space as a place where to study (31\%), and spend free time (38\%). Thus, they belong to two activities that are not connected to the museum exhibition, but rather linked to a public space, a multifunctional space, a co-working place, a stimulating environment for creativity and integration space. In particular, the free wi-fi service, the presence of free space with tables and chairs, and the library with free admission are certainly elements that favor the presence of many students and workers, but an important role plays also the environment of integration and creativity offered by the pole, and guaranteeing, at the same time, a safety place. The area is perceived by users interviewed as an amusing and creative space, an active space, where creativity, culture, integration and interaction between different people becomes a stimulating environment for cultural and human individuals' growth.

Here, the point of view of the MAXXI Museum deputy director:

The library is free from the last two years, like a public library. There was a 25 euros' annual card to do before, it was not so expensive. Nowadays, it is full of students of all faculties. Today, many scholars study in the bar, just for the type of space. And they also colonized the ex-bar, where there is an architectural archive inserted into the tables that can be consulted freely. The people standing there do not consult the archive, but they use them only as tables. It has become like a public library. To enter, there is a ramp and when I step on it, it makes a little noise and I'm so sorry to make noise, because it seems to enter a library. Maybe it will be changed. The museum realizes that it had become a public space. On the one hand, it is a small failure of the museum, from the point of view of the archive project, for example. MAXXI does not aim to keep people here, but it wants people to visit the exhibits. The perception of the museum is to work continuously to gain the trust and understanding of the district. Visibility is important. The museum is alive. It is a welcoming space. People come to sunbathe, coffee break. In the MAXXI square, parents feel safe. The museum is proud of it. At the same time, it wonders if those, in the square, can also be museum visitors. If not, what does the museum do and what is it? (Mrs. Donatella Saroli interview 2018).

The witness of the MAXXI Museum artistic deputy director displays the aware of the use of the museum from people that are not exhibitions' visitors. Thus, the exhibition spaces and the outdoor area are not really integrated. An apparent integration between museum exhibition areas and the space used as a public could result from some activities already proposed by the MAXXI museum complex, such as the summer campus for children offered by the education department, the yoga activities, rather than visual or acoustic contemporary art installations displayed just outside the exhibition halls. Indeed, although some museum policies may have had significant effects in terms of the growing number of visitors in museums as declared in the Press Conference of 25 January 2018 (i.e. the free-Sundays ${ }^{4}$ ), at the same time, this research shows that most of the users of the public area of the museum pole are not those people that are exhibition visitors too. Thus, if on the one hand, the museum benefits from the presence of nonpaying users within the pole, as a visibility opportunity, at the same time, the museum need to propose strategies to attract those people using the outdoor space of the museums in visiting the exhibitions' areas.

At this point, to have a framing of the relation between the people gravitating in the outdoor area of the MAXXI and the exhibition visitors, I investigated the monthly permanence time in the MAXXI spaces and the annually visits to the exhibition areas. The results reveal a majority of people (61\%) that have a low monthly permanence frequency (between 1 and 4 times in a month) in the MAXXI spaces, and the $36 \%$ frequent the areas in between 5 and 20 days in a month - in particular 16\% users frequent the MAXXI about 5 to 10 days in a month and (20\%) about 10 to 20 days in a month -. Wilts, just a minimum number of users (3\%) spend more than 20 days in a month in the MAXXI spaces, considering that the closing days in a month could be 4 or 5 , it is about a daily use of the spaces.

The museum visitors' results are expected, even if shocking. In fact, more than $50 \%$ of respondents did not visit the museum's exhibitions or, at least, they visited more than one year ago. In particular, from the analyses of the double frequencies, it results that the $100 \%$ of those people that could be considered as daily users of the MAXXI spaces declared to have visited the exhibition area of the MAXXI more than 1 year from the day of the questionnaire. Indeed, in the less frequency user ( 1 to 4 days in a month) that is the $61 \%$ of the sample it is revealed that $23 \%$ visited the museum exhibition in the last 3 months, the $15 \%$ in the last 6 months, and the $23 \%$ in the last year. In particular, those who declare to

${ }^{4}$ Mrs. Giovanna Melandri, President of MAXXI in the Press Conference of 25 January 2018. 
have visited the museum in the last 3 months have a less frequency (1 to 4 days in a month), so probably some of them are there for the first time, in fact the $12 \%$ of them declare they are visitors of the exhibition in the questionnaire days; so, it remains an $11 \%$ of respondents that are using the space in the questionnaire day for different reasons from the exhibition but who visited the museum in the last 3 months. In this scenario, two different populations could be identified in a little percentage who is an exhibition visitor and a bigger percentage who is a user of the space for other reasons (study/work, leisure, etc.) that leads to outline the real use of the MAXXI space as a collective or public space.

Confirming this, the main alternatives to the MAXXI proposed by the users are areas that offers a cultural and creative leisure space, parks, libraries or coworking spaces (i.e. Auditorium - Parco della Musica; Casilino Active Space, etc.), not instead other museums or exhibition spaces. In fact, $44 \%$ of the sample indicated in the open question the nearby Auditorium - Parco della Musica as cultural and creative leisure space and as an alternative place to the MAXXI. This could be interpreted as a witness of the transformation of the contemporary concept of public space and the need of a cultural and creative space, and a safe space too. The $16 \%$ of the sample chose other parks as an alternative to the MAXXI square and the $15 \%$ another library or university, the $10 \%$ have no alternative to MAXXI or the alternative is just to stay at home. Whilst, it is relevant that just the $5 \%$ of the respondents choose a museum structure (i.e. MACRO TESTACCIO, GNAM, etc.) as an alternative to the MAXXI. This reveals the actual use of the space by citizens and declares the need of a leisure or co-working space referred to creativity and culture.

To deepen the analysis of the use of the MAXXI as a semi-public space, considering that the museum complex offers services as bar and restaurants, I investigate about how many people in the sample are actually bar or restaurant users, and not people that use the MAXXI spaces as a sort of public space. The findings highlight and enforce the aim of the MAXXI as a public space, in fact, the majority $(61,5 \%)$ of the sample are not consuming in bar or restaurant, $14 \%$ are consuming home-made packed lunch and just $24,5 \%$ are consuming in the bar/restaurant.

In conclusion and in consideration of the fact that the age range of the respondents is very wide, from the youngest to the elderly, I investigate about the division of the space between the different ages, thus, the different uses of the space as a public space, and I made a direct observation to strengthen the quantitative information. It was possible to distinguish three population by ages: i) the youngest people including young university stu- dents, high school students and young workers - who were more predisposed to respond to the questionnaire -; ii) the elderly people that were mainly retired; and iii) families and baby sitters with children.

The direct observation and deepen interviews helped to support the quantitative findings and to define the MAXXI space as a form of public space. In particular, by direct observation, it has resulted evident a division of the space of MAXXI outdoor area. Children with families are on the opposite side of the main entrance of Guido Reni street - in the direction of G.P. Pannini street were the building $\mathrm{C}$ should have arisen -, and where among the trees, the benches and the wide space do not disturb the young students and workers who are divided between the two bars of the museum center equipped with tables and chairs inside and outside. Thus, it is spontaneously created a series of distinct and separate subspaces, with different characters and attracting different groups of users (Carmona, 2019).

Here, to understand why a museum complex is used as a place for children, considering that there are no children's game as in a park, I made deepen interviews addressed to groups of mothers and babysitter who used the MAXXI spaces as a park for their children. It turned out that the MAXXI is considered as the most convenient public space, not only for the Flaminio residents, but even by the inhabitants of the Prati-Delle Vittorie district, a district located just across the Tiber river from the Flaminio district. They chose the MAXXI to let their children play outdoor because it is considered safe.

In sum, these results confirm the initial forecasts of the research: the MAXXI is mainly used as a public space for integration, meeting, studying/working and leisure time and the citizens seem to express satisfaction for a space that is controlled, orderly, safe, innovative, a space where it is possible to interact and an inclusive space.

\section{Conclusions}

The use of the museum pole as a form of public space emerges clearly by the multifunctional, cultural and creative activities referred to the users of the space. The results of the empirical analysis clearly show a collective and multifunctional use of the MAXXI, which appears, therefore, as a public space rather than a mere cultural center. Therefore, the phenomenon of collective use in the museum pole opens up a reflection on different points of analysis:

Albeit a framework of contemporary public space is poorly defined, it is quite clear, as described in much of recent literature, that in the contemporary city emerges a 
new concept of space, generally belonging to semi-public or private areas and confirmed by the overcoming of the concept of public space in favor of a new hybrid space. Focusing on these approaches it emerges that the neoliberal design of functional public space aimed at revitalizing the city is not always appropriate to the needs of the citizen. In fact, part of the most recent critical literature (Barnett 2014; Gehl 2020) shows how the contemporary city expresses the need for new forms of (public) space, as well as a change in the way of thinking about the approach to public space, paying greater attention to the actions of individuals. As Barnett (2014) suggests, in fact, "we must negotiate between the idea that there are some activities that are only public by their very nature and the idea that public things are things called contingently public" (Barnett 2014, 895). From this point of view, we must rethink the way in which the concept of "public" can be evaluated and interpreted, therefore, to what extent the actions make a space or some types of spatial configurations public.

The MAXXI museum takes on a central role in the Flaminio district as an area of sharing and integration, and, partly, confirms a change in the way of thinking the public space approach and the need of a new contemporary (public) space expressed by citizens. The case study shows the function of a space can be distorted by the actions of citizens, seeing the transformation of a "void" into a space that assumes the function of public. This could be highlighted by the MAXXI museum unfinished work that become a space of encounter and integration. Not only: the MAXXI case study highlights a general need of citizens in the research of an alternative, creative, cultural, safe and innovative space. In fact, the MAXXI manages to support the different needs of contemporary citizens while simultaneously representing a place of co-working (study, work, professional meetings, etc.), a place of integration (spaces accessible to all, i.e., disabled, elderly, children, tourists, students, foreigners, etc.), a place of recreation and gathering for children and young people (families with children, etc.) that favors an environment of collaboration, synergy and creativity.

The MAXXI create a sort of enclave to the rest of the city that offer a refuge from the hustle and bustle of the city and ensure the safety required by citizens in a sort of security bubble from the city. The need of a safe place favors the use of the MAXXI area as a public space. In fact, according to Carmona, public "spaces are provided in locations that are safe, convenient and inviting to use and that avoid conflict" (Carmona 2019, 50). In particular, in light of the current dynamics related to the pandemic period, safety in a public space could take on a relevant force and become a new need for people.

In consideration of the fact that in the contemporary society, people are looking for a space that must be comfortable, welcoming and livable (Gehl 2020). Indeed, as often happen, in many cities, in private spaces "managers seek to use the privilege of ownership to exclude key groups (such as teenagers), restrict access [...] or impose codes of behavior [...], they undermine the freedoms that public spaces users rightfully expect" (Carmona 2019, 51); in the MAXXI area, instead, the is no behavior code imposed by the ownership. Thus, the impact of culture and the fusion between culture, creativity and technology seems to represent a main element of attractiveness of the MAXXI space for the community, that, in fact, appears as a multifunctional space rather than a museum complex.

In conclusion, the MAXXI become a part of the town and the urban fabric and got a central role as a meeting place. The MAXXI could be seen as a model of a new contemporary public space that create benefits, for the district and, in general, for the community of the city at all, contributing to bring to society a cultural and multifunctional space based on safety, cohesion, innovation, integration and creativity. But yet, a knot remains to be solved about the lack of integration between the users of the "public" outdoor space and the exhibition visitors. Thus, a final reflection, which opens a starting point for future analysis, involves the opportunity for the MAXXI to melt the two heart of the museum pole: the cultural heritage and the public space through renewed communication assets and policies able to strengthen the image of the museum as urban gallery; indeed, in a prospected view, considering the current community needs linked to the pandemic time, it could be interesting the opportunity to stimulate the creation of a cultural ecosystem able to confirm a clear identity of the MAXXI space.

\section{References}

Albanese, V. (2018). Introduzione. In Berizzi, C. (ed.). Piazze e spazi collettivi. Nuovi luoghi per la città contemporanea. Padova, Il Poligrafo.

Barnett, C. (2014). How to think about public space. In Cloke, P., Crang, P., Goodwin, M. (eds.). Introducing Human Geographies. London, Routledge.

Bauman, Z. (2012). Modernità liquida, Roma-Bari, GLF.

Berizzi, C. (2018). Piazze e spazi collettivi. Nuovi luoghi per la città contemporanea. Padova, Il Poligrafo. 
Berdoulay, V., Entrikin, J. N. (1998). Lieu et sujet: perspectives théoriques. L'Espace géographique, 27(2), 111-121.

Carmona, M. (2015). Re-theorising Contemporary Public Space: A New Narrative and a New Normative. Journal of Urbanism, 8 (4), 374-405.

Carmona, M. (2019). Principles for public space design, planning to do better. Urban Design International, 24, 47-59.

Cellamare, C. (2014). Autorganizzazione, pratiche di libertà e individuazione. Territorio, 68, 21-27.

Cellamare, C. (2016). Le diverse periferie di Roma e le forme di autorganizzazione. Working papers, 2. https:// www.urbanit.it/wp-content/uploads/2016/10/3_BP_ Cellamare_C.pdf

Crosta, P.L. (2000). Società e territorio, al plurale. Lo spazio pubblico - quale bene pubblico - come esito eventuale dell'interazione sociale, Foedus, 1.

Crosta, P.L. (2010). Pratiche. Il territorio è "l'uso che se ne $f a$ ". Milano, FrancoAngeli Editore.

Francis, J., Giles-Corti B., Wood L., Knuiman M. (2012). Creating sense of community. The role of public space. Journal of environmental psychology, 32 (4), 401-409.

Galuzzi, P., Vitillo, P. (2018). Città contemporanea e rigenerazione urbana. Temi, azioni, strumenti, Equilibri, 22 (1), 125-133.

Gehl, J. (2020). "Three Types of Outdoor Activities," "Life Between Buildings," and "Outdoor Activities and the Quality of Outdoor Space". In LeGates R.T., Stout F. (eds.). The City Reader ( $7^{\text {th }}$ ed.). London, Routledge.

Guccione, M., Ciorra, P. (2017). L'Italia di Zaha Hadid, catalogo della mostra (Roma, 23 giugno 2017-14 gennaio 2018). Macerata, Quodlibet.

Hadid, Z., Betsky, A. (2009). The complete Zaha Hadid. New York, Rizzoli International.

Hou, J. (2010). Insurgent public space: guerrilla urbanism and the remaking of contemporary cities. London, Routledge.

Innerarity, D. (2008). Il nuovo spazio pubblico, Milano, Booklet.

Lindón, A., Aguilar, M. Á., Hiernaux, D. (2006). Lugares e imaginarios en la metrópolis. Barcelona, Anthropos.

Maggioli, M. (2015). Dentro lo Spatial Turn: luogo e località, spazio e territorio. Semestrale di studi e ricerche di geografia, 27 (2), 51-66.
Nemeth, J. (2012). Controlling the Commons, How Public is Public Space? Urban Affairs Review, 48 (6), 811835.

Paul, D.E. (2004). World cities as hegemonic projects: the politics of global imagineering in Montreal. Political Geography, 23, 571-596.

Salvo, S. (2014). Il futuro incerto dell' edilizia residenziale pubblica del Novecento: il caso del Villaggio Olimpico di Roma. Erph_Revista electrónica De Patrimonio Histórico, (14), 138-160.

Scott, A. J. (2001). Capitalism, cities, and the production of symbolic forms. Transactions of Institute of British Geographers, 23, 11-23.

Stravato, E. (2010). Città storica: le aree dismesse come provocazione di sviluppo. Relazione al Workshop Internazionale Roma 2010-2020, Nuovi modelli di trasformazione urbana.

Zajczyk, F. (1991). La conoscenza sociale del territorio: fonti e qualità dei dati. Milano, FrancoAngeli. 